\title{
Molecular Cloning and Expression Analysis of Heat Shock Protein 90 (Hsp90) of the Mud Crab, Scylla Paramamosain
}

\author{
An-Ming Huang ${ }^{1}$, Yi Geng ${ }^{1}$, Kai-Yu Wang ${ }^{1}$, Fan Zeng ${ }^{1}$, Qiang Liu ${ }^{1}$, Yuan Wang ${ }^{1}$, \\ Yun Sun ${ }^{1}$, Xing-Xing Liu ${ }^{1} \&$ Yan Zhou ${ }^{1}$ \\ ${ }^{1}$ College of Veterinary Medicine, Sichuan Agricultural University, Ya'an 625014, Sichuan, P. R. China \\ Correspondence: Yi Geng, College of Veterinary Medicine, Sichuan Agricultural University, Xinkang Street No. \\ 46, Ya'an 625014, Sichuan Province, P. R. China. Tel: 86-0835-288-5753. E-mail:gengyisicau@126.com
}

\author{
Received: March 28, 2013 Accepted: April 18, 2013 Online Published: June 15, 2013 \\ doi:10.5539/jas.v5n7p1 URL: http://dx.doi.org/10.5539/jas.v5n7p1
}

\begin{abstract}
Heat shock protein 90 (HSP90), functions as a molecular chaperone in protein biosynthesis play an important role in signal transduction, immune responses and embryogenesis. However, the function research of HSP90 in invertebrates is limited. To further understand the role and mechanism of HSP90 in immune and stress response, we have isolated the the fragment of HSP90 homologue from mud crab Scylla paramamosain through transcriptome sequencing of mixture of hepatopancreas and hemocytes, The full-length cDNA of HSP90 is harvested through RACE technology and it contains 73 bp 5'terminal UTR, 577 bp 3'terminal UTR and 2373 bp open reading frame which encoding a 790-amino-acid protein. BLASTP results demonstrate that SpHSP90 share high identity with Tribolium castaneum and Locusta migratoria and other reported crustacean (61\%-73\%). Phylogenetic tree based on HSP90 proteins show that SpHSP90 and Daphnia pulex form a cluster within the invertebrate group while other reported HSP90s of vertebrate are grouped into another branch. The tissue distribution was tested by quantitative real-time PCR and SpHSP90 was detected express in all test tissues, the results showed that HSP90 was constitutively expressed in Scylla paramamosain. The highest expression of HSP90 was found in hepatopancreas, the following was in heart, and the lowest expression of it was found in hemocyte. The expression patterns of SpHSP90 after challenged by the Staphylococcus aureus, Vibrio harveyi and WSSV were also analyzed by qRT-PCR and the result showed that the expression level of SpHSP90 was enhanced after challenged with the Gram-positive bacteria (Staphylococcus aureus), Gram-negative bacteria (Vibro harveyi) and virus (white spot syndrome virus, WSSV). These results suggested that SpHSP90 involved in the immune response against invading pathogens. Furthermore, SpHSP90 was expressed by prokaryotic expression system and purified by His Bind resin chromatography.
\end{abstract}

Keywords: Scylla paramamosain, HSP90, molecular cloning, expression pattern, prokaryotic expression

\section{Introduction}

Heat shock protein90 (HSP90) is one kind of molecular chaperone that widely exists in cells and highly conserved, plays an important role in regulating cell cycle, body immunity and signal transduction, also have an influence on the occurrence and development of tumor, has great significance in clarifying the development of tumor (Picard, 2002; Wiech et al., 1992; Miyata et al., 1992; Holmes, 2008). HSP90 directly involve in protein assembly and transfer, stabling protein structure and regulating cell cycle, and indirectly participate in regulating many signal pathways by adjusting its receptor protein activity and maintaining structure stability of its receptor protein (Miyata et al., 1995; Schumacher et al., 1994; Nathan et al., 1997 ). HSP90 also have interaction with cytoplasmic proteins or nuclear, including regulatory tyrosine kinases, some serine/threonine kinases, transcription factors, cytoskeletal proteins, and $\beta \gamma$ subunits of $G$ proteins (Aligue et al., 1994). In recent years, many functions of HSP90 and the relationships between injury and infection have been constantly clarified, and the studies of HSP90 gene sequence, protein function and its role in the embryonic development process have caused wide public concern, including the research of this gene of many kinds of aquatic crustaceans (Gao et al., 2007; Li et al., 2012). It will be induced to express when heat shock responses occur under the stress from environment or pathogens and take part in relevant immune reaction, suggested that they play an important role in response to potentially stress conditions (Polla, 1991; Kregel, 2002; Feder et al., 1999; Jolly et al., 1999). 
Have researches reported: HSP90 also involved in the immune response in lipopolysaccharide (LPS) recognition (Byrd et al., 1999; Triantafilou et al., 2002; Triantafilou et al., 2001).

The Scylla paramamosain, green mud crab belongs to Arthropoda, Crustacea, Decapoda, Portunidae, is one of the most promising and valuable crabs for aquaculture in China (Estam, 1949). The culture area of the green mud crab in China expanded inrecent years ( $\mathrm{Li}$ et al., 2004). However, With the enlargement of the cultivation scale and intensive culture, couple with the deterioration of ecological environment, Bacterial disease become more serious, even white spot syndrome virus (WSSV) began to infect this kind of crab now, which cause lots of economic losses (Lange et al., 2000; Pandey et al., 2000). Therefore, clarify the expression pattern of HSP90 after pathogen infection will be benefit to the farming of aquatic crustaceans. In the present study, we cloned a full-length cDNA sequence and characterized of a HSP90 from the green mud crab Scylla paramamosain. The immune relevant functions of HSP90 were validated. After being infected with bacteria or WSSV, the transcripts of HSP90 gene were up-regulated, These results suggest that HSP90 plays an important role in defending against bacterial and virus infections.

\section{Materials and Methods}

\subsection{Experimental Animals, Reagents and Pathogens}

The Taq DNA polymerase, dNTP Mix, RNase Inhibitor, M-MLV RTasecDNA Synthesis Kit, SYBR Premix Ex Taq II, DEPC treated water, Oligo (dT) 18, pMD18-T Vector, DH5 $\alpha$ competent, Rosetta (DE3) competent, Agarose Gel DNA Purification Kit, DNA Marker were all purchased from Takara (Japan). TRIzol reagent was obtained from Invitrogen (America), SMART ${ }^{\mathrm{TM}}$ RACE cDNA Amplification kit was purchased from Clontech (America), Kanamycin, Ampicillin was purchased from AMRESCO (America), T4 DNA Ligase, Reverse transcription System, IPTG was purchased from Fermentas (Canada), His Bind resin chromatography was purchased from Novagen (America). Staphylococcus aureus, vibrio harveyiand White Spot Syndrome Virus (WSSV) were conserved by our lab.

Staphylococcus aureus and vibrio harveyi were overnight cultured at $37^{\circ} \mathrm{C}$. centrifugally collecting thalli $(3000 \times \mathrm{g}, 20 \mathrm{~min})$, the thalli was washed by Phosphate Buffered Saline (PBS) $(140 \mathrm{mMNaCl}, 10 \mathrm{mM}$ sodium phosphate, $\mathrm{pH}$ 7.4), subsequently, re-suspended in PBS to harvest $10^{9}$ Colony-Forming Units per milliliter (CUF/ml) cell suspension. WSSV was extracted from gill of Penaeus chinensis infected with WSSV. After gill homogenized, collected the supernatant after centrifugation, measured virus quantity, then diluted to $10^{7}$ viral particles per milliliter.

Healthy adult mud crabs Scylla paramamosain (average body weight: $300 \pm 50 \mathrm{~g}$ ) purchased from a commercial crab farm in Chongming county (Shanghai, China) were reared in $300 \mathrm{~L}$ tanks with continuous aeration for a week before processing. Water temperature, $\mathrm{pH}$ and salinity was maintained at $18^{\circ} \mathrm{C}, 8.0 \sim 8.2$, and 10 , respectively.

\subsection{Immune Challenge and Sampling}

Crabs were randomly divided into 5 groups including staphylococcus aureus group, vibrio harveyi group and WSSV group, PBS group as negative control of bacterial stimulation, and the supernatant of homogenate of healthy shrimp gill tissue group as negative control of WSSV stimulation. Each group contains three replicates. Each crab was injected with $50 \mu 1$ staphylococcus aureus supernatant $\left(5 \times 10^{7} \mathrm{cfu}\right)$, or $50 \mu 1$ vibrio harveyi supernatant $\left(5 \times 10^{7} \mathrm{cfu}\right)$ or $50 \mu \mathrm{l}$ WSSV supernatant $\left(5 \times 10^{5}\right.$ virus particle) at the base of the right second leg. Crab from the corresponding control was injected with $50 \mu \mathrm{l}$ PBS or healthy gill tissue supernatant. Hemocytes was collected from each crab at $0,2,6,12,24,48 \mathrm{~h}$ post-injection, and mixed with an equal volume of pre-cooled anticoagulant solution $(0.14 \mathrm{M} \mathrm{NaCl}, 0.1 \mathrm{M}$ glucose, $30 \mathrm{mM}$ trisodium citrate, $26 \mathrm{mM}$ citric acid, 10 mM EDTA, pH 4.6). Subsequently hemocytes were centrifuged at $800 \mathrm{~g}$ at $4{ }^{\circ} \mathrm{C}$ for $15 \mathrm{~min}$, and hemocyte pellets were immediately suspended in Trizol for RNA extraction. In addition, hemocytes, heart, hepatopancreas, gill, stomach, intestine, muscle, gonad and connective tissue from healthy crabs were collected for SpHSP90 tissue distribution analysis.

\subsection{RNA Extraction and cDNA Synthesis}

Total RNA was isolated from healthy crabs hemocyte, heart, hepatopancreas, gill, stomach, intestines, muscle, connective tissue and gonad using Trizol following the protocol of the manufacturer, as well as isolated from the hemocyte of challenged crabs at $0,2,6,12,24$ and $48 \mathrm{~h}$ post-challenge, stored at $-80^{\circ} \mathrm{C}$. The quality was checked by spectrophotometry. Total RNA was reserve transcribed with the M-MLV RTasec DNA Synthesis Kit to get the first strand cDNA. The product was diluted properly and stored at $-20^{\circ} \mathrm{C}$ till analysis. 


\subsection{Cloning the Full-Length cDNA of SpHSP9O}

A fragment of HSP90-like cDNA sequence was harvested from the cDNA library of mud crab Scylla paramamosain constructed through transcriptome sequencing of mixture of hepatopancreas and hemocytes. A pair of primers, SpHSP90F (5'-GACCCGCAATGACCTGGTGAAC-3') and SpHSP90R (5'-CTCCACTGGTTCGTCCACAGCA-3'), were synthesized to amplify the middle fragment cDNA sequence of HSP90. Another two pairs of primers were synthesized to obtain the $3^{\prime}$ and $5^{\prime}$ ends of this HSP90 cDNA sequence, SpHSP90F1 (5'-TGTTCGAGGACTTCCACTAG-3') and anchorR (5'-GACCACGCGTATCGATGTCGAC-3'), SpHSP90R1 (5'-CTCCACTGGTTCGTCCACAGCA- $3^{\prime}$ ) and SmartF (5'-TACGGCTGCGAGAAGACGACAGAAGGG-3'). The polymerase chain reaction (PCR) was carried out under the following parameters: $94^{\circ} \mathrm{C}$ for $2 \mathrm{~min} ; 35$ cycles at $94^{\circ} \mathrm{C}$ for $35 \mathrm{~s}, 60^{\circ} \mathrm{C}$ for $45 \mathrm{~s}$, and $72^{\circ} \mathrm{C}$ for $1 \mathrm{~min} 20 \mathrm{~s}$; and finally, $72^{\circ} \mathrm{C}$ for $10 \mathrm{~min}$. The products were verified and extracted, then inserted into pMD18-T and transformed into Escherichia coli DH5a competent. Positive clones were screened by blue-white spot, subsequently sequenced by Sunny Biotechnology Co., Ltd, Shanghai. The full-length cDNA sequence of SpHSP90 was obtained by assembling these three fragments.

\subsection{Sequence Analysis}

The nucleotide sequence and deduced amino acid sequence of SpHSP90 from S. paramamosain were analyzed by DNAstar and NCBI Blast (http://blast.ncbi.nlm.nih.gov/Blast.cgi). The theoretical pI and molecular mass of the deduced protein were predicted by EXPASY Compute pI/Mw program (http://web.expasy.org/compute_pi/). Protein domains and signal peptide were predicted by Smart (http://smart.embl-heidelberg.de/) and SignalIP (http://www.cbs.dtu.dk/services/SignalP/) respectively. A phylogenetic tree of HSP90s was constructed by MEGA5.1. The 3D structures of the SpHSP90 domains were modeled by homology through SWISS-MODEL workspace (http://swissmodel.expasy.org/workspace/).

\subsection{Tissue Distribution and mRNA Expression Profiles Analysis}

Transcript expression profiles of in nine different tissues including hemocyte, heart, hepatopancreas, gills, stomach, intestines, muscle, connective tissue and gonad from S. paramamosain were detected by real-time qRT-PCR using a pair of specific primers: SpHSP90RF (5'-GGACTGGACTCTGGTGAATGA-3') and SpHSP90RR (5'-CTTGATGTTGTCTGTGCGTGT-3'). A pair of Sp18S primers, Sp18SF (5'-GCTTTCGCAGTAGTTCGTCTTG-3') and Sp18SR (5'-CCTCGGTTCTATTTTGTCGGT-3') designed from the 18S rRNA sequence (GenBank Number: FJ646616.1) were used as internal control. The qRT-PCR was performed in a volume of $20 \mu \mathrm{l}$ containing $10 \mu \mathrm{l} 2 \times$ SYBR Premix Ex Taq, $2 \mu 1 \mathrm{cDNA}, 4 \mu 1$ each primer $(1 \mu \mathrm{M})$ and $4 \mu \mathrm{l}$ reverse primer $(1 \mu \mathrm{M})$. The amplified reaction was carried out under these conditions: a pre-denaturation of $10 \mathrm{~min}$ at $95^{\circ} \mathrm{C}$, followed by 40 cycles of $95^{\circ} \mathrm{C}$ for $10 \mathrm{~s}, 60^{\circ} \mathrm{C}$ for $60 \mathrm{~s}$ and a melt from $60^{\circ} \mathrm{C}$ to $95^{\circ} \mathrm{C}$. The expression levels were calculated using $2^{-{ }^{\mathrm{CT}}}$ method. The mRNA expression level of SpHSP90 in hemocytes after pathogen stimuli was measured by qRT-PCR with the same primers and methods described previously, the templates were synthesized cDNA from the total RNA extracted from hemocytes of $S$. paramamosain after challenged by Staphylococcus aureus, Vibrio harveyi and WSSV. The expression profiles after Pathogenic stimuli were analyzed by $2^{-\triangle \Delta} \mathrm{CT}$.

\subsection{Recombinant Plasmid Construction}

A pair of primers: HSP90EXF (5'-CGCCATATGAACAAGGAGATCTTCCTG-3') and HSP90EXR (5'-TACTCACTCGAGTCATTTCTTCCACCTCA-3') used to obtain the HATPase c and HSP90domains of SpHSP90. The thermal cycling conditions used were $95^{\circ} \mathrm{C}$ for $5 \mathrm{~min}$, followed by 35 cycles of $95^{\circ} \mathrm{C}, 30 \mathrm{~s} ; 59^{\circ} \mathrm{C}$, $45 \mathrm{~s} ; 72^{\circ} \mathrm{C}, 1 \mathrm{~min} 20 \mathrm{~s}$ and an extension of $72^{\circ} \mathrm{C}$ for $7 \mathrm{~min}$. Restriction sites for Nde I and Xho I were engineered at $5^{\prime}$ and $3^{\prime}$ end of this expressed sequence by using this pair of primers. The product was purified using Agarose Gel DNA Purification kit and cloned into pET-30a vector. The transformants were selected on LB agar plates supplemented with Kanamycin (final concentration of $25 \mu \mathrm{g} / \mathrm{mL}$ ). The inserted sequenced was confirmed by sequencing.

\subsection{Protein Expression and Purification}

The positive recombinant plasmid pET-30a-SpHSP90 was transformed into expression host strain Rosseta (DE3) for over-expression and induced by a final concentration of $1 \mathrm{mM}$ Isopropyl $\beta$-D-1-Thiogalactopyranoside (IPTG) at $28^{\circ} \mathrm{C}$ for $10 \mathrm{~h}$. thalli was collected by centrifugal, washed twice by PBS, then re-suspended in PBS and broken by the ultrasonic wave. The recombinant protein SpHSP90 with His-tag was purified by His Bind resin chromatography following the operating instructions. This recombinant protein was evaluated using SDS-PAGE and was further verified by Western blot, transferred the purified proteins containing in the gel onto a 
nitrocellulose membrane. Then blocked the nitrocellulose membrane in blocking solution (3\% Nonfat-Dried Milk in TBS) for $1 \mathrm{~h}$. Following, incubated the membrane with the antibody against His-tag in Blocking Solution (1/100 dilution) at $4^{\circ} \mathrm{C}$ overnight. Washed the membrane three times with $\mathrm{TBS}(10 \mathrm{mM}$ Tris- $\mathrm{HCl}$ and $150 \mathrm{mM} \mathrm{NaCl} ; \mathrm{pH} 7.5$ ) before added the second antibody (peroxidase-conjugated goat anti-mouse IgG; 1/10,000 TBS dilution). Finally, the SpHSP90 protein was showed via a colorimetric reaction.

\section{Result}

\subsection{Sequence Analysis}

The full length sequence of SpHSP90 includes 3023 bp nucleotides with a poly-adenylationsignaldownstream, containing a $2373 \mathrm{bp}$ open reading frame (ORF) which encoding a 790-amino-acid protein and a 577bp $3^{\prime}$ untranslated region (UTR) and a 73 bp 5' UTR (Figure 1). GenBank accession number: JX987068.1. Predicted theoretical pI and molecular mass of the deduced protein was 4.77 and $90.77 \mathrm{kDa}$. The domain architecture analysis showed that there is a signal peptide (1 to 24 aa), a HATPase cdomain (101 to 259 aa) and afunctional structural domain HSP90 (261 to 786 aa). The 3D structure was predicted by SWISS-MODEL using a E. coli HSP90 as the model (PDB: 1Y4S chain A $2.90 \AA$ ), the predicted sequence similarity was $40.65 \%$ (Figure 2 ).

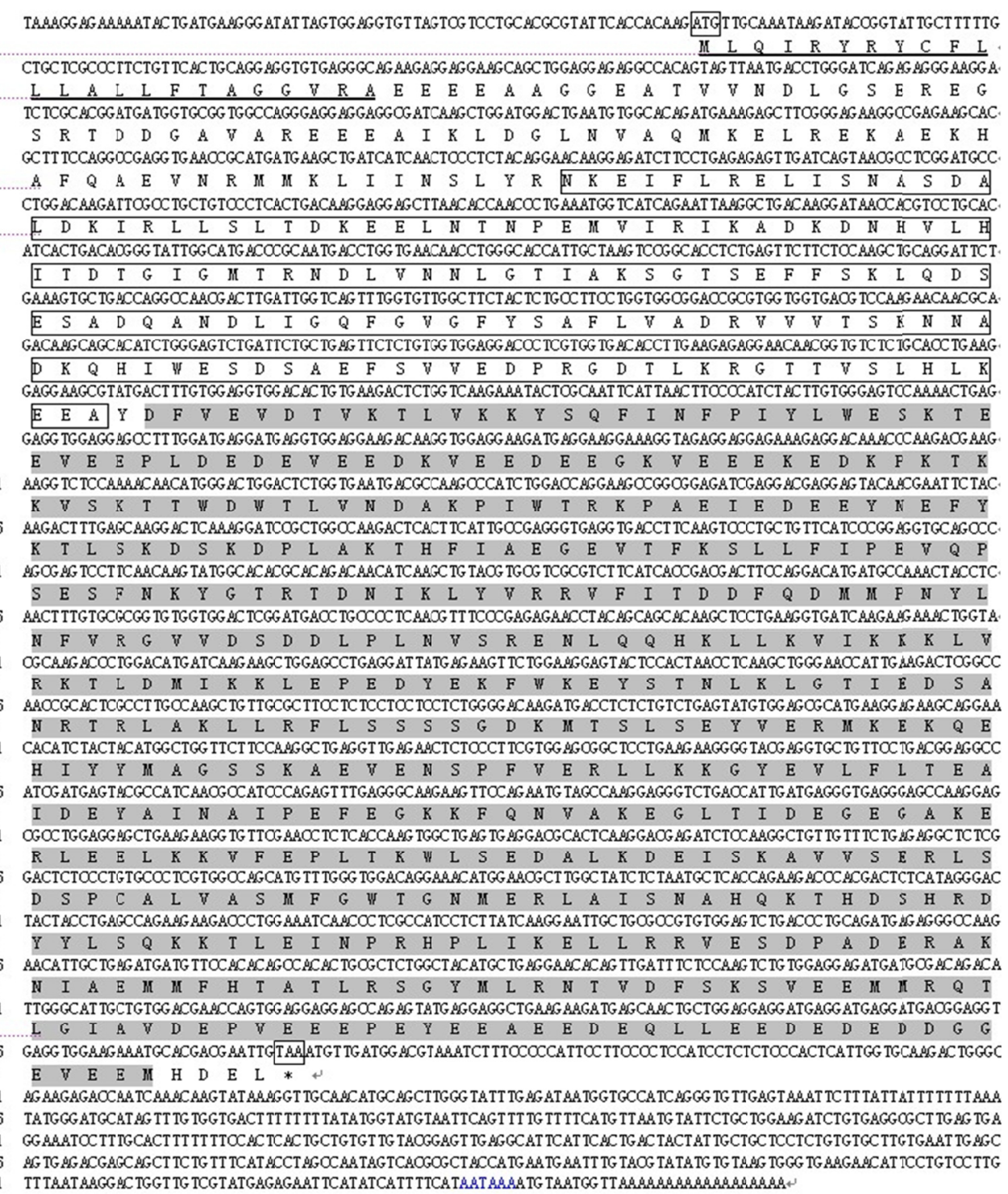

Figure 1. cDNA sequence and deduced amino acid sequence of $S$. paramamosain heatshock protein 90 gene, ATG is a start codon, TAA is a stop codon, signal peptide is underlined, aminoacid sequence within the text box is the first structure domain HATPase_c, aminoacid sequence in dash area is the second domain Phm HSP90 


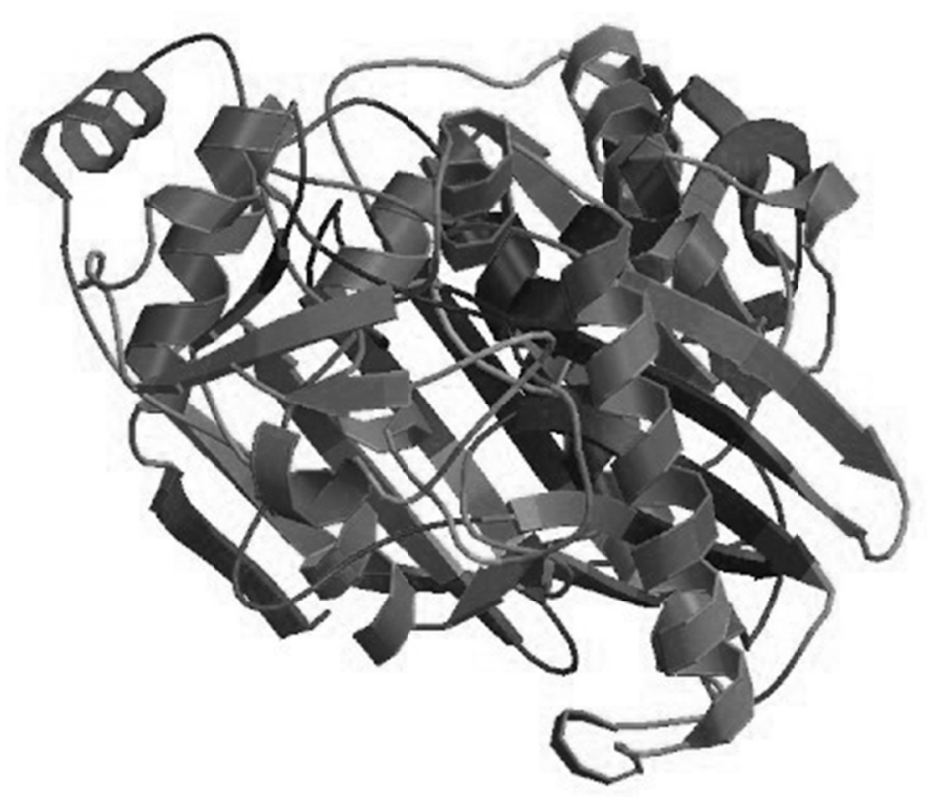

Figure 2. 3D structure of SpHSP90 predicted by SWISS MODEL using E. coli HSP90 as model (1Y4S chain A)

(Benkert et al., 2011)

\subsection{Phylogenetic Analysis}

The alignment of SpHSP90 amino acids sequence by BLASTP showed it shared high similarity with other HSP90 (61\%-73\%), 73\% identical with Dendroctonus ponderosae AEE63339.1, 72\% with Tribolium castaneum XP 971540.1, Locusta migratoria ACS75351.1 and Daphnia pulex EFX71215.1, 63\% with Homo sapiens CAI64497.1, Based on the Blastp results, a phylogenetic tree was constructed by MEGA 5.1 with the neighbor-joining method to study the evolutionary relationship among them. As shown in Figure 3, SpHSP90 and DpHSP90 (D. pulex) as well as many other invertebrate HSP90 formed one group, and another group was consisted of vertebrate HSP90, Thisphylogenetic tree revealed that SpHSP90 had a much closer evolutionary relationship with the HSP90 of invertebrate, especially with DpHSP90. 


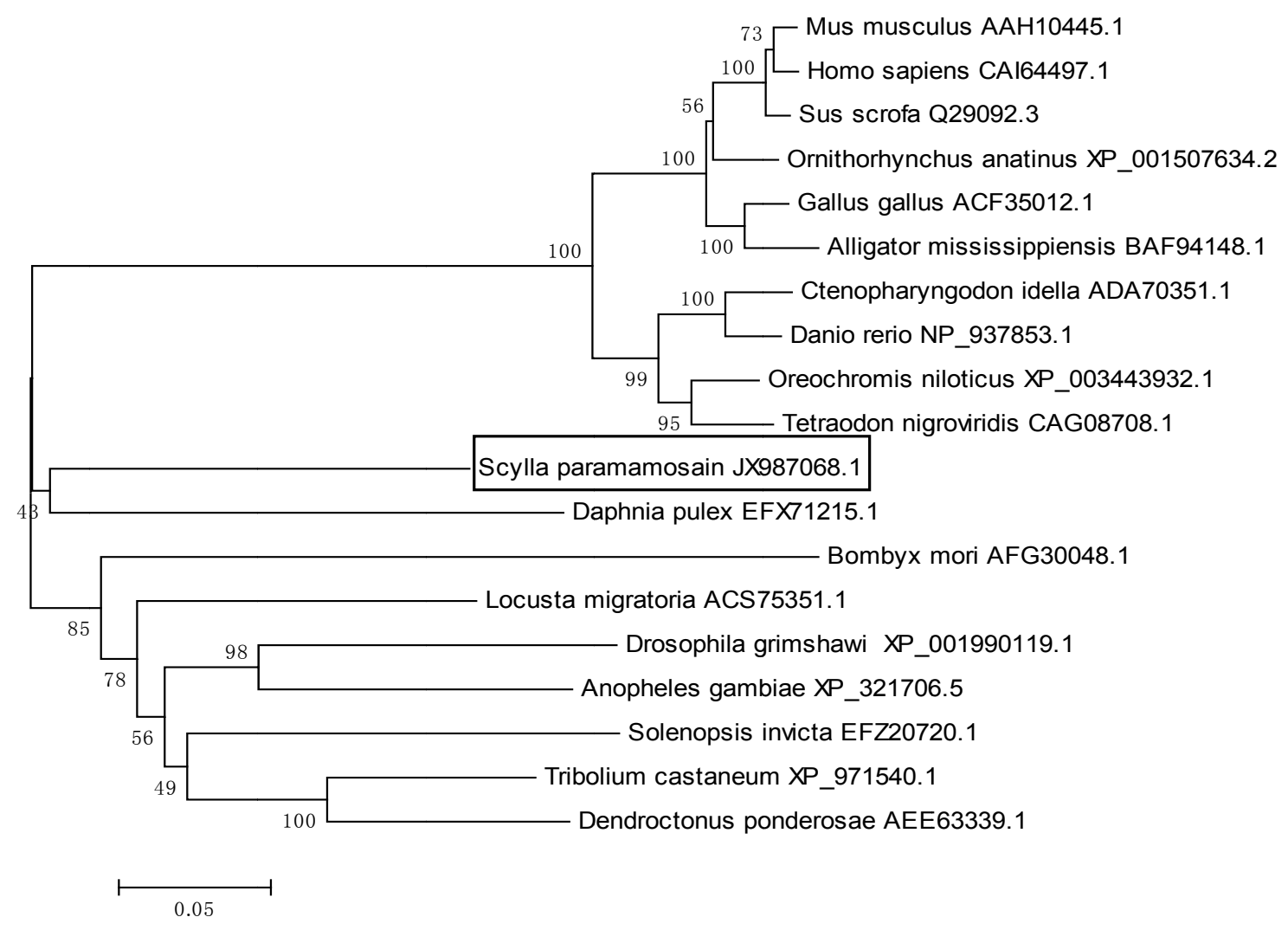

Figure 3. Phylogenetic tree of SpHSP90 with other reported HSP90S from invertebrates and vertebrates constructed by the neighbor-joining method using the MEGA 5.1. SpHSP90 is marked with a box. The corresponding GenBank accession numbers are shown in the figure

\subsection{Tissue Distribution of SpHSP90}

Expression profile of SpHSP90 in nine different tissues was investigated using Real-time PCR normalized to Sp18S. The results showed that SpHSP90was expressed in all tissues, in which the highest level was detected in hepatopancreas, followed by heart and the lowest expression level was detected in hemocyte (Figure 4).

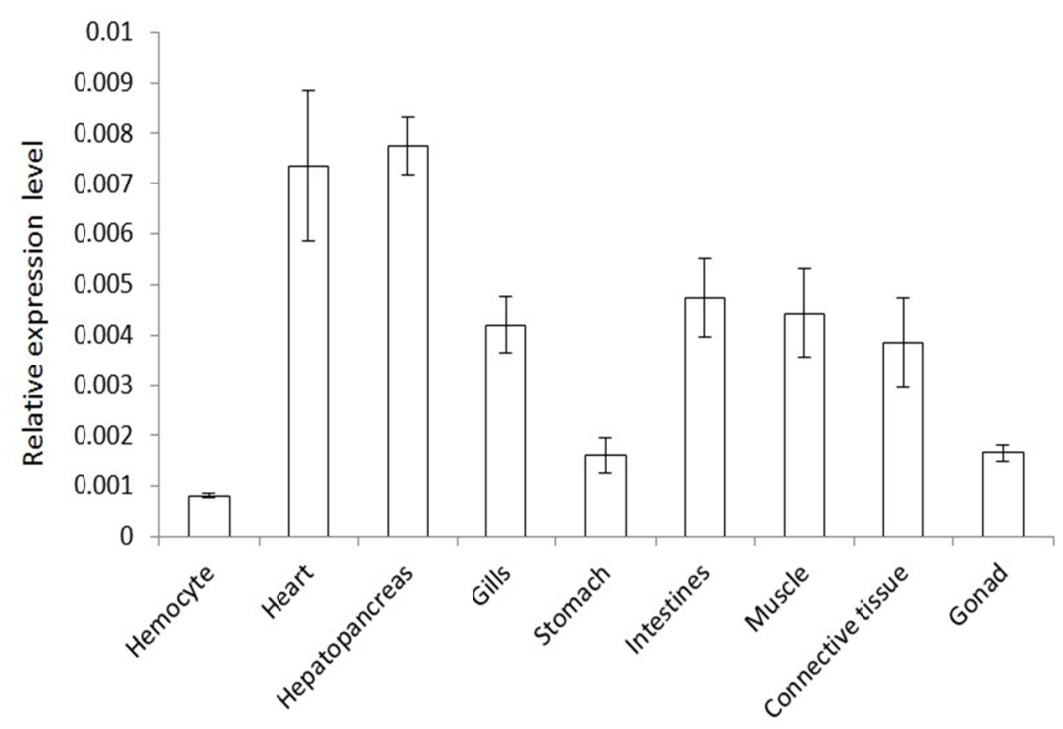

Figure 4. Tissue distribution of SpHSP90 using Sp18S as the reference gene 


\subsection{The Expression Profiles of SpHSP90 in Hemocytes after challenge}

The expression level of SpHSP90 in the hemocyte of $S$. paramamosain after pathogenic bacteria or WSSV infection was analyzed by qRT-PCR. After $S$. aureus challenged, the expression level of SpHSP90 increased rapidly from $2 \mathrm{~h}$ to $6 \mathrm{~h}$ post-injection, and reached the peak at $12 \mathrm{~h}$, which was about 5 times higher than the normal group. Then, began a slow decline and returned to normal level at $24 \mathrm{~h}$ (Figure 5A). Compared to the control group, the expression level of SpHSP90 after challenged with $V$. harveyi rose sharply and reached the maximal level at $6 \mathrm{~h}$ post-injection (12 times normal), afterwards, decreased gradually (Figure 5B). SpHSP90 expression level was up-regulated from $2 \mathrm{~h}$ to $12 \mathrm{~h}$ post-injection after WSSV challenged and was almost 16 fold higher than control group at $12 \mathrm{~h}$ post-injection, then the expression level of SpHSP90 decreased rapidly and recovered to the normal level at $24 \mathrm{~h}$ post-injection (Figure 5C).
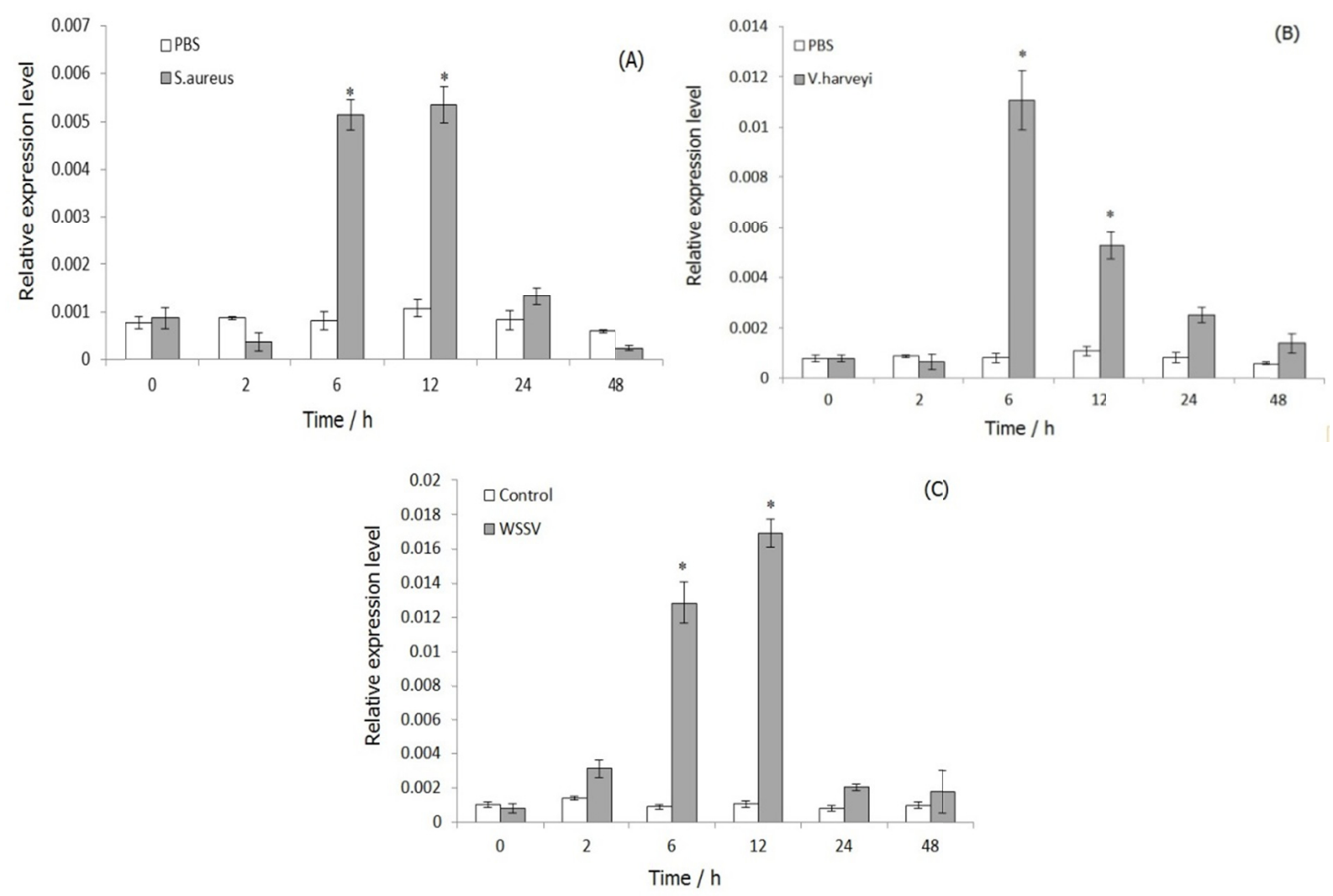

Figure 5. Expression profiles of SpHSP90 in hemocytesafter challenge. The expression level was measured by real-time PCR at different time $(0,2,6,12,24,48 \mathrm{~h})$ post-injection. The expression level of SpHSP90 after injection with the A: S.aureus, B: V.harveyi, C: WSSV

\subsection{Protein Expression and Purification}

Transformed the recombinant plasmid pET-30a-SpHSP90 into Rosseta (DE3) and was induced to protein express by IPTG. Purified this soluble protein by His Bind resin chromatography. The theoretical molecular weight of recombinant SpHSP90 was $79.08 \mathrm{kDa}$, as showed in Figure 6A, the molecular size was generally consistent with the SDS-PAGE result. One band was displayed in Western blot result and the size was agree with the theoretical molecular mass of the recombinant SpHSP90 (Figure 6B). This further confirmed that the recombinant protein was expressed correctly. 


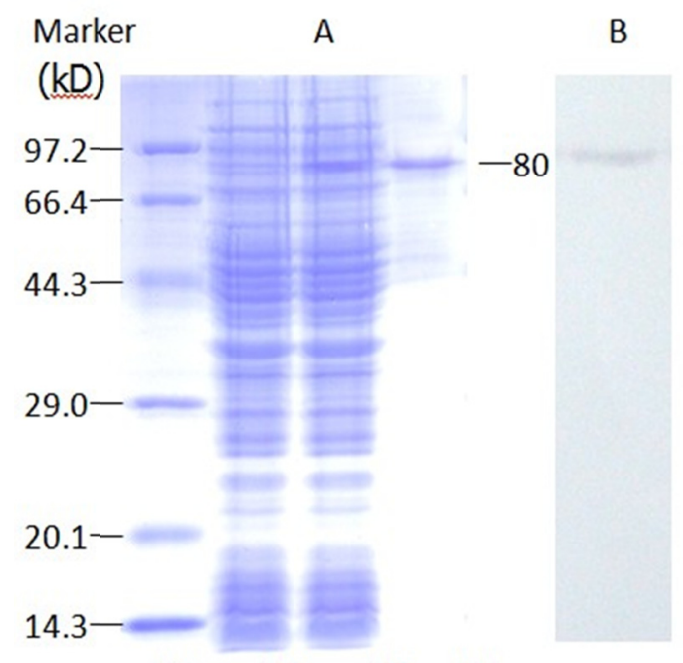

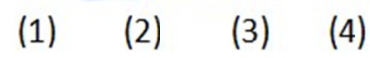

Figure 6. Expression and purification of the recombinant prote in SpHSP90, Panel A, Lane 1 was protein marker, Lane 2 was total protein of E.coli with pET-30a-SpHSP90 without induction, Lane 3 was total protein of E.coli with pET-30a-SpHSP90with induction and Lane 4 was purified recombinant protein SpHSP90. The band in panel B was recognized by the antibody against His-tag in theWestern blot assay using recombinant protein

SpHSP90 assampled

\section{Discussion}

In recent years, the frequencies of disease epidemics have been reported becoming much higher and more new diseases have emerged in marine animals (Harvell et al., 1999). Affected the immunity of animal adversely and human may partly be responsible for all these harmful results, caused higher susceptibility to infection (Pipe et al., 1995). Therefore, the researches of immunological stressrelated genes and strengthen the immune system of animal reasonably become critical.Heat shock protein $90 \mathrm{can}$ be found in all organisms from bacteria to humans and highly conservative, they play an important role in the immune response and disease resistance (Mestril et al., 1995).

In this study, the full-length cDNA sequence of HSP90 from S. paramamosain was first cloned using the RACE technique. The full-length cDNA of SpHSP90 was of $3023 \mathrm{bp}$, including an ORF of $2373 \mathrm{bp}$ encoding a polypeptide of 790 amino acids, this polypeptide possessed the same structure characteristics as other described HSP90 of vertebrate or invertebrate, Conserved sequences and characteristic sequences, like histidine protein kinase functional domain and HSP90 family signatures (Gupta, 1995).

The BLASTP results revealed that SpHSP90 deduced amino acids sequence shared $61 \%-73 \%$ amino acids identity with other reported HSP90 sequence of other species, $73 \%$ with Dendroctonus ponderosae, $72 \%$ with Tribolium castaneum, Locusta migratoria and Daphnia pulex. The phylogenetic tree displayed that SpHSP90 was in the invertebrate group and this result illustrated SpHSP90 was more identical with those HSP90s of invertebrate than with those of vertebrate and possessed closer genetic relationship with invertebrate HSP90. In vertebrates, HSP90 gene has two kinds of isoforms: HSP90 $\alpha$ and HSP90 $\beta$. The major difference between these two isoforms is that only HSP90 $\alpha$ isoform possess structure of glutamine-rich sequence (QTQDQ) at the N-terminus. Sequence alignment analysis demonstrated that SpHSP90 shared higher similarity with HSP90 $\beta$ and there was no QTQDQ sequence at SpHSP90 N-terminus like other HSP90ß isoforms. This QTQDQ sequence is a site of phosphorylation by a dsDNA-dependent kinase (Buchner, 1999). All these characteristics show that SpHSP90 was much closer to the vertebrate HSP90 $\beta$ isoforms.

The functions and mechanisms of HSP90 during pathogenic stimulistill not clear. The recent data indicated that stress proteins involved in regulatory the cellular immune responses and played key roles in protecting organisms from pathogen invasion (Encomio et al., 2004; Moseley, 2000). In mammals, many studies showed that the expression level of stress proteins could be induced by bacteria or bacterial products (Kantengwa et al., 1993; Clerget et al., 1990; Deitch et al., 1995). The research on Acanthamoeba castellanii suggested that HSP90 possessed phagocytosis and bactericidal activity in host cells (Yan et al., 2004). In the present, we investigated 
the expression profiles of SpHSP90 after injection with WSSV or bacteria. SpHSP90 expression levels increased after WSSV challenged, indicating that SpHSP90 may take part in immune reaction against WSSV. In addition, SpHSP90 expression levels were also up-regulated after the $S$. aureusor $V$. harveyi challenge. The higher increase of SpHSP90 expression levels was detected in $V$. harveyi challenged groups, which suggested that $V$. harveyi was probably a stronger inducer for SpHSP90 and alsoillustrated that $V$. harveyi may be apathogenic bacteria in S. paramamosain. (Zhang et al., 2005). According to a previous report, HSP90 was considered as an important immune related gene (Triantafilou et al., 2001). Similar to other HSP90s that were detected in many tissues, SpHSP90 mRNA was detectedin all the examined tissues (hemocytes, heart, hepatopancreas, gill, stomach, intestine, muscle, gonad and connective tissue), and showed the highest level in the hepatopancreas.

In summary, the cDNA sequence of SpHSP90 was reported for the first time, and the expression profiles of SpHSP90 mRNA suggested that SpHSP90 may play an important role in the immune system of $S$. paramamosain. All the data of this research would be beneficial to further clarify the role of SpHSP90 in immune defense and the specific mechanism still needs more studies to unscramble.

\section{Acknowledgments}

This work was supported by Sichuan Technology Support Planning (No.2011N20071).

\section{References}

Aligue, R., Akhavan-Niak, H., \& Russell, P. (1994). A role for Hsp90 in cell cycle control: Wee1 tyrosine kinase activity requires interaction with Hsp90. EMBO journal, 13(24), 6099-6106.

Benkert, P., Biasini, M., \& Schwede, T. (2011). Toward the estimation of the absolute quality of individual protein structure models. Bioinformatics, 27(3), 343-350. http://dx.doi.org/10.1093/bioinformatics/btq662

Buchner, J. (1999). Hsp90 \& Co.-a holding for folding. Trends in Biochemical Sciences, 24(1), 136-141. http://dx.doi.org/10.1016/S0968-0004(99)01373-0

Byrd, C. A., Bornmann, W., Erdjument-Bromage, H., Tempst, P., Pavletich, N., \& Rosen, N. (1999). Heat shock protein 90 mediates macrophage activation by Taxol and bacterial lipopolysaccharide. Proceedings of the National Academy of Sciences of the United States of America, 96(10), 5645-5650. http://dx.doi.org/10.1073/pnas.96.10.5645

Caplan, A. J. (1999). Hsp90's secrets unfold: new insights from structural and functional studies. Trends in Cell Biology, 9(7), 262-268. http://dx.doi.org/10.1016/S0962-8924(99)01580-9

Clerget, M., \& Polla, B. S. (1990). Erythrophagocytosis induces heat shock protein synthesis by human monocytes-macrophages. Proceedings of the National Academy of Sciences of the United States of America, 87(3), 1081-1085. http://dx.doi.org/10.1073/pnas.87.3.1081

Deitch, E. A., Beck, S. C., Cruz, N. C., \& De, M. A. (1995). Induction of heat shock gene expression in colonic epithelial cells after incubation with Escherichia coli or endotoxin. Critical Care Medicine, 23(8), 1371-1376. http://dx.doi.org/10.1097/00003246-199508000-00010

Encomio, V. G., \& Chu, F. L. (2004). Characterization of heat shock protein expression and induced thermotolerance in P. marinus parasitized eastern oysters: lab and field studies. Journal of Shellfish Research, 23, 289-290.

Estam, D. P. (1949). Studies on Scylla (Crustacea: Portunidae ), Revision of the genus. Philippine Journal of Science, 78(1), 95-108.

Feder, M. E., \& Hofmann, G. E. (1999). Heat-shock proteins, molecular chaperones, and the stress response: evolutionary and ecological physiology. Annual Review of Physiology, 61, 243-282. http://dx.doi.org/10.1146/annurev.physiol.61.1.243

Gao, Q., Song, L. S., Nia, D. J., Wu, L. T., Zhang, H., \& Chang, Y. Q. (2007). cDNA cloning and mRNA expression of heat shock protein 90 gene in the haemocytes of Zhikong scallop Chlamysfarreri. Comparative Biochemistry and Physiology, Part B, 147(4), 704-715. http://dx.doi.org/10.1016/j.cbpb.2007.04.010

Gupta, R. S. (1995). Phylogenetic analysis of the $90 \mathrm{kD}$ heat shock family of protein sequences and an examination of the relationship among animals, plants, and fungi species. Molecular Biology and Evolution, 12(6), 1063-1073. 
Harvell, C. D., Kim, K., Burkholder, J. M., Colwell, R. R., Epstein, P. R., Grimes, D. J., ... Vasta, G. R. (1999). Emerging marine diseases-climate links and anthropogenic factors. Science, 285, 1505-1510. http://dx.doi.org/10.1126/science.285.5433.1505

Holmes, J. L., Sharp, S. Y., \& Hobbs, S. (2008). Silencing of HSP90 cochaperone AHA1 expression decreases client protein activation and increases cellular sensitivity to the HSP90inhibitor 17-allylamino-17-demethoxygeldanamycin. Cancer Research, $\quad$ 68(4), http://dx.doi.org/10.1158/0008-5472.CAN-07-3268

Jolly, C., \& Morimoto, R. I. (1999). Stress and the cell nucleus: dynamics of gene expression and structural reorganization. Gene Expression, 7(4-6), 261-270.

Kantengwa, S., \& Polla, B. S. (1993). Phagocytosis of Staphylococcus aureus induces a selective stress response in human monocytes-macrophages (M phi): modulation by $\mathrm{M}$ phi differentiation and by iron. Infection and Immunity, 61(4), 1281-1287.

Kregel, K. C. (2002). Heat shock proteins: modifying factors in physiological stress responses and acquired thermotolerance. Journal of Applied Physiology, 92(5), 2177-2186.

Lange, B. M., Bachi, A., William, M., \& González, C. (2000). Hsp90 is a core centrosomal component and is required at different stages of the centrosome cycle in Drosophila and vertebrates. EMBO Journal, 19, 1252-1262. http://dx.doi.org/10.1093/emboj/19.6.1252

Li, J. T., Han, J. Y., Chen, P., Chang, Z. Q., He, Y. Y., Liu, P., .. Li, J. (2012). Cloning of a heat shock protein 90 (HSP90) gene and expression analysis in the ridgetail white prawn Exopalaemoncarinicauda. Fish \& Shellfish Immunology, 32(6), 1191-1197. http://dx.doi.org/10.1016/j.fsi.2012.03.008

Li, X. C., Du, Z. Q., Lan, J. F., Zhang, X. W., Mu, Y., Zhao, X. F., \& Wang, J. X. (2012). A novel pathogen-binding $\mathrm{gClqR}$ homolog, $\mathrm{FcgClqR}$, in the Chinese white shrimp, Fenneropenaeuschinensis.Developmental and Comparative Immunology, 36(2), 400-407. http://dx.doi.org/10.1016/j.dci.2011.08.005

Li, Z. B., Li, S. J., \& Wang, G. Z. (2004). Genetic diversity and differentiation of mud crab Scylla serrata populations from southeastern china. Acta Oceanologica Sinica, 23(2), 309-316.

Mestril, R., \& Dillmann, W. H. (1995). Heat shock proteins and protection against myocardial ischemia. Journal of Molecular and Cellular Cardiology, 27(1), 45-525. http://dx.doi.org/10.1016/S0022-2828(08)80006-5

Miyata, Y., \& Yahara, I. (1992). The 90-kDa heat shock protein, HSP90, binds and protects casein kinase II from self-aggregation and enhances its kinase activity. Journal of Biological Chemistry, 267(12), 7042-7047.

Miyata, Y., \& Yahara, I. (1995). Interaction between casein kinase II and the 90-kDa stress protein, HSP90. Biochemistry, 34(25), 8123-8129. http://dx.doi.org/10.1021/bi00025a019

Moseley, P. (2000). Stress proteins and the immune response. Immunopharmacology, 48(3), $299-302$. http://dx.doi.org/10.1016/S0162-3109(00)00227-7

Nathan, D. F., Vos, M. H., \& Lindquist, S. (1997). In vivo functions of the Saccharomyces cerevisiae Hsp90 chaperone. Proceedings of the National Academy of Sciences of the United States of America, 94(24), 12949-12956. http://dx.doi.org/10.1073/pnas.94.24.12949

Pandey, P., Saleh, A., Nakazawa, A., Kumar, S., Srinivasula, S. M., Kumar, V., ... Kharbanda, S. (2000). Negative regulation of cytochrome $\mathrm{C}$ mediated oligomerization of Apaf 1 and activation of procaspase 9 by heat shock protein 90. EMBO Journal, 19(16), 4310-4322. http://dx.doi.org/10.1093/emboj/19.16.4310

Picard, D. (2002). Heat-shock protein 90, a chaperone for folding and regulation. Cellular and Molecular Life Sciences, 59(10), 1640-1648. http://dx.doi.org/10.1007/PL00012491

Pipe, R. K., \& Coles, J. A. (1995). Environmental contaminants influencing immune function in marine bivalve molluscs. Fish \& Shellfish Immunology, 5(8), 581-595. http://dx.doi.org/10.1016/S1050-4648(95)80043-3

Polla, B. S. (1991). Heat shock proteins in host-parasite interactions. Parasitology Today, 7(3), 38-41. http://dx.doi.org/10.1016/0169-4758(91)90028-M

Schumacher, R. J., Hurst, R., Sullivan, W. P., McMahon, N. J., Toft, D. O., \& Matts, R. L. (1994). ATP-dependent chaperoning activity of reticulocyte lysate.Journal of Biological Chemistry, 269, 9493-9499. 
Triantafilou, K., Triantafilou, M., \& Dedrick, R. L. (2001). A CD14-independent LPS receptor cluster. Nature Immunology, 2, 338-345. http://dx.doi.org/10.1038/86342

Triantafilou, K., Triantafilou, M., \& Dedriek, R. L. (2001). Interactions of Bacterial Lipopolysaccharide and Peptidoglycan with a $70 \mathrm{kDa}$ and an $80 \mathrm{kDa}$ protein on the Cells Surface of CD14+ and CD14- Cells. Human Immunology, 62(1), 50-63. http://dx.doi.org/10.1016/S0198-8859(00)00222-6

Triantafilou, M., Miyake, K., Golenbock, D. T., \& Triantafilou, K. (2002). Mediators of innate immune recognition of bacteria concentrate in lipid rafts and facilitate lipopolysaccharide-induced cell activation. Journal of Cell Science, 115, 2603-2611.

Wiech, H., Buchner, J., Zimmermann, R., \& Jakob, U. (1992). Hsp90 chaperones protein folding in vitro. Nature, 358, 169-170. http://dx.doi.org/10.1038/358169a0

Yan, L., Cerny, R. L., \& Cirillo, J. D. (2004). Evidence that hsp90 is involved in the altered interactions of Acanthamoebacastellanii variants with bacteria. Eukaryot Cell, 3(3), 567-578. http://dx.doi.org/10.1128/EC.3.3.567-578.2004

Zhang, W., Wu, X., Li, D., Sun, J., Zhang, Y., \& Yang, X. (2005). Epizootiological study on mass mortalities of the cultured scallops Argopectenirradians. Acta Oceanologica Sinica, 27, 137-144.

\section{Copyrights}

Copyright for this article is retained by the author(s), with first publication rights granted to the journal.

This is an open-access article distributed under the terms and conditions of the Creative Commons Attribution license (http://creativecommons.org/licenses/by/3.0/). 